\title{
Recurrent Mixed Cellularity Classic Hodgkin Lymphoma
}

National Cancer Institute

\section{Source}

National Cancer Institute. Recurrent Mixed Cellularity Classic Hodgkin Lymphoma. NCI

Thesaurus. Code C8832.

The reemergence of mixed cellularity classic Hodgkin lymphoma after a period of remission. 